\title{
The relationship between postoperative atrial fibrillation after coronary artery bypass surgery and inflammation
}

\author{
Burak Erdolu๑, Ahmet Kağan As` \\ Department of Cardiovascular Surgery, University of Health Sciences, Bursa Yüksek İhtisas Training and Research Hospital, Bursa, \\ Turkey
}

\begin{abstract}
Objectives: Postoperative atrial fibrillation (PoAF) may occur up to 50\% after coronary artery bypass grafting (CABG) operations. The most important problems related to this are prolonged hospitalizations, thromboembolic cerebrovascular events and new onset heart failure. In this study, we aimed to investigate the relation of high sensitivity C-reactive protein (hsCRP) and heat shock protein 70 (HSP70) levels and occurrence of PoAF in patients undergoing isolated CABG.

Methods: Patients who underwent elective isolated coronary artery bypass surgery between November 2008 and April 2009 in the Cardiovascular Surgery Clinic of Diskap1 Yıldırım Beyazit Training and Research Hospital were prospectively included in the study.

Results: A total of 40 patients (20 Off-pump CABG (OPCABG), mean age: $59.3 \pm 5.56$ years) and 20 Onpump CABG (mean age: $60.7 \pm 5.3$ years)) were included in the study. PoAF ratio was $25 \%$ in on-pump CABG patients and $15 \%$ in OPCABG group $(p=0.356)$. Age and diameters of the heart cavities were statistically significantly higher in patients with POAF in both surgical groups. Left ventricular ejection fraction was significantly lower in patients with PoAF. Preoperative hsCRP, postoperative hsCRP, preoperative HSP70 and postoperative HSP70 levels were significantly higher in patients with PoAF who underwent OPCABG ( $p=$ $0.018, p=0.044, p<0.001$ and $p=0.047$; respectively).

Conclusions: As a result, PoAF is undesirable for $\mathrm{CABG}$ operations. PoAF can be predicted by evaluating HSP70 and hsCRP values before coronary bypass operations.

Keywords: Coronary artery bypass grafting, postoperative atrial fibrillation, inflammation, heat shock protein 70
\end{abstract}

$\mathrm{C}$ oronary artery disease (CAD) is the leading cause of mortality worldwide. Although technological advances in endovascular interventions have increased treatment options in recent years, coronary artery bypass grafting (CABG) surgery is still an effective and important treatment modality $[1,2]$. $\mathrm{CABG}$ is a major surgical procedure and it is important to predict the possible morbid and mortal conditions after surgerical approach and to take the necessary precautions. Cardiac rhythm problems after these operations are important and the most common one is atrial fibrillation. Postoperative atrial fibrillation (PoAF) may occur up to $50 \%$ after CABG operations [3]. The most important problems related to this are prolonged hospitalizations, thromboembolic cerebrovascular events and new onset heart failure. The 
risk factors for PoAF development includes advanced age, history of cerebrovascular event, existence of preoperative heart failure, and chronic pulmonary disease [4].

The role of inflammatory parameters in the development and prognosis of cardiovascular diseases has been the subject of research. One of those, high sensitivity C-reactive protein ( $\mathrm{hsCRP}$ ), is a valuable parameter that is safe and easily detectable [5]. Blood hsCRP levels is found to be higher in patients suffering from atrial fibrillation (AF) than normal individuals in several studies $[6,7]$.

Heat Shock Protein 70 (HSP70), which is one of the heat shock protein family, can limit the damage in the cells exposed to stress. A study revealed that, intracellular HSP70 levels in the right atrial tissue were shown to be negatively correlated with PoAF [8].

In this study, we aimed to investigate the relation of hsCRP and HSP70 levels and occurrence of PoAF in patients undergoing isolated $\mathrm{CABG}$.

\section{METHODS}

\section{Patients}

After obtaining local ethical comitee approval, 40 patients who underwent elective isolated coronary artery bypass surgery between November 2008 and April 2009 in the Cardiovascular Surgery Clinic of Dışkapı Yıldırım Beyazıt Training and Research Hospital were prospectively included in the study.

Patients who were scheduled forelective CABG between the ages of 40-70 years, left ventricular functions were not depressed (ejection fraction $[\mathrm{EF}]>$ $45 \%$ ), had no cardiac valve pathology, left atrial and right atrial diameters were not increased, had no chronic obstructive pulmonary disease, had no preoperative arrhythmia and did not have ahistory of any antiarrhythmic drug usage were included in the study.

Patients with previous history of arrhythmia, advanced age $(>70)$ patients, heart failure patients, patients who suffered from an acute coronary syndrome attack in the last 60 days, patients who were operated under emergency conditions, patients with temporary or permanent pacemaker, patients who had proximal right coronary arterylesions, patients with inotropic need for more than 24 hours postoperatively and/or intra-aortic balloon pump implanted, patients whose preoperative echocardiogram revealed grade 2 or more mitral insufficiency or moderate and severe mitral stenosis or greater than 2 degree aortic insufficiency or with moderate and severe aortic stenosis or grade 2 or higher tricuspid regurgitation or moderate to severe tricuspid stenosis, patients of impaired renal function (serum creatine levels $>2 \mathrm{mg} / \mathrm{dl}$ ), patients who were diagnosed with pulmonary embolism in the last 60 days prior to $\mathrm{CABG}$, and severe lung disease that may lead to right heart failure was excluded from the study group.

Age, gender, presence of diabetes mellitus, hypertension, hypercholesterolemia, preoperative EF, left ventricular end-systolic diameter (LVESD), left ventricular end-diastolic diameter (LVEDD), left atrial diameter (LAD), right atrial diameter (RAD), righ ventricular diameter(RVD), duration of total anesthesia time, postoperative inotropic drug support (5-15 $\mu \mathrm{g}$ $/ \mathrm{kg} / \mathrm{min}$ dobutamine infusion if low flow or hypotension persists noradrenaline infusion) and PoAF development were recorded for all patients. Also for On-pump patients, cross-clamp (CC) time and cardiopulmonary bypass (CPB) time were recorded.

\section{Laboratory Test Analysis}

Blood samples were collected on the day before the operation and on the postoperative 3rd day to measure hsCRP and HSP70 levels. Blood samples were taken after a fasting period longer than 12 hours. Platelet-poor plasma samples were obtained by centrifugation at $3500 \mathrm{rpm}$ for 5 minutes at $+4^{\circ} \mathrm{C}$. Samples were stored at $-80^{\circ} \mathrm{C}$. After all samples were prepared, HSP70levels were measured in the HSP70 ELISA Kit test system. In the study, the unit for HSP70 was taken as $\mathrm{ng} / \mathrm{ml}$. The lower limit of the Hsp 70 level that the test can detect is $0.039 \mathrm{ng} / \mathrm{ml}$. Serum levels of hsCRP (Dade Behring, CardioPhase hsCRP) were studied by immunonephelometer (Dade Behring, Marburg GmbH, Germany). The normal value of hsCRP was $<3.19 \mathrm{mg} / \mathrm{dl}$.

\section{Postoperative Cardiac Rhytm Analysis}

All patients were fully monitored includingelectrocardiography (ECG) monitoring during intensive care follow-up and 12-lead ECG recordings were recorded daily during the postoperative hospital stay.In addition, 12-lead ECG was performed in patients with palpitation, sweating, dyspnea and chest 
pain during the follow-up.

PoAF was defined as the absence of $p$ wave and development of irregular ventricular rhythm before QRS complex in all of the ECG derivations.

\section{Statistical Analysis}

In this study, statistical analyzes were performed using SPSS 16.0 statistical package program. The $p$ values obtained in the test results were evaluated at significance level below 0.05 . Mean and standard deviations were calculated using descriptive methods for continuous and ordinal data. The distribution of normality were tested by "Kolmogorov-Smirnov test" and "Shapiro-Wilk test". "Student 's t test" was used for the data showing normal distribution and "MannWhitney U test" was used for the data that did not fit the normal distribution. Frequency and persentage analysis was performed for nominal data and Chi Square test was used to compare these data.

\section{RESULTS}

A total of 40 patients (20 OPCABG (mean age:
$59.3 \pm 5.56$ years) and 20 On-pump CABG (mean age: $60.7 \pm 5.3$ years) were included in the study. There were no statistically significant difference between the two surgical groups in terms of hypertension, diabetes mellitus, hyperlipdemia, preoperative echocardiography findings, distal anostomosis numbers, total anesthesia duration and inotropic requirements. PoAF ratio was $25 \%$ in on-pump CABG patients and 15\% in OPCABG group ( $p=$ 0.356). Demographic characteristics and peroperative data of both surgical groups are given in Table 1.

The parameters affecting the development of PoAF were evaluated separately for both surgical groups and the data are given in Table 2. Age, LVESD, LVEDD, LAD, RAD and RVD were statistically significantly higher in patients with PoAF in both surgical groups. Left ventricular ejection fraction was significantly lower in patients with PoAF. When the surgical groups were individually evaluated and PoAF and the rest were compared, there was no difference between the groups in terms of the number of distal anostomosis, inotropic requirement, and total anesthesia duration times. There were no significant difference between the patients of PoAF and the rest

Table 1. Demographic characteristics and peroperative features of the patients

\begin{tabular}{|c|c|c|c|}
\hline Characteristics & $\begin{array}{c}\text { Off-Pump } \\
(\mathbf{n}=\mathbf{2 0})\end{array}$ & $\begin{array}{c}\text { On-Pump } \\
(\mathbf{n}=\mathbf{2 0})\end{array}$ & $p$ value \\
\hline Age (years) & $59.3 \pm 5.56$ & $60.7 \pm 5.3$ & 0.424 \\
\hline Hypertension, n (\%) & $16(80)$ & $18(90)$ & 0.661 \\
\hline Diabetes mellitus, n (\%) & $10(50)$ & $13(65)$ & 0.523 \\
\hline Hiperlipdemia, n (\%) & $18(90)$ & $18(90)$ & 1.000 \\
\hline $\mathrm{EF}(\%)$ & $49.2 \pm 2.6$ & $50.2 \pm 3.5$ & 0.292 \\
\hline $\operatorname{LVEDD}(\mathrm{cm})$ & $4.8 \pm 0.5$ & $4.7 \pm 0.6$ & 0.726 \\
\hline $\operatorname{LVESD}(\mathrm{cm})$ & $3 \pm 0.3$ & $3.1 \pm 0.4$ & 0.404 \\
\hline $\mathrm{LAD}(\mathrm{cm})$ & $3 \pm 0.5$ & $3.2 \pm 0.5$ & 0.135 \\
\hline RAD (cm) & $3.54 \pm 0.58$ & $3.56 \pm 0.59$ & 0.893 \\
\hline $\operatorname{RVD}(\mathrm{cm})$ & $2.2 \pm 0.18$ & $2.13 \pm 0.21$ & 0.273 \\
\hline Distal anostomosis number $>2, \mathrm{n}(\%)$ & $10(50)$ & $15(75)$ & 0.102 \\
\hline Inotropic support, n (\%) & $9(45)$ & $12(60)$ & 0.342 \\
\hline Anesthesia time (min) & $216.4 \pm 26.8$ & $241.8 \pm 40.7$ & 0.026 \\
\hline PoAF, n (\%) & $3(15)$ & $5(25)$ & 0.356 \\
\hline
\end{tabular}

Data are shown as mean \pm standard deviation or number $(\%) . E F=$ Ejection fraction, LVESD $=$ Left ventriculer end-systolic diameter, LVEDD = Left ventriculer end-diastolic diameter, LAD = Left atrial diameter, RAD = Right atrial diameter, RVD = Right ventriculer diameter, PoAF $=$ Postoperative atrial fibrillation 
Table 2. Comparison of demographic and peroperative characteristics of patients in two surgical groups according to PoAF status

\begin{tabular}{|c|c|c|c|c|}
\hline Characteristics & & $\begin{array}{c}\text { Off-Pump } \\
(\mathrm{n}=\mathbf{2 0})\end{array}$ & $\begin{array}{c}\text { On-Pump } \\
(\mathbf{n}=\mathbf{2 0})\end{array}$ & $p$ value \\
\hline \multirow[t]{2}{*}{ Age (years) } & $\operatorname{PoAF}(-)$ & $58.2 \pm 5.3^{\mathrm{a}}$ & $59 \pm 4.9^{b}$ & ${ }^{\mathrm{a}} \mathbf{0 . 0 3 8}$ \\
\hline & $\operatorname{PoAF}(+)$ & $65.3 \pm 2.3^{\mathrm{a}}$ & $65.8 \pm 2.8^{\mathrm{b}}$ & b0.010 \\
\hline \multirow[t]{2}{*}{$\mathrm{EF}(\%)$} & PoAF (-) & $49.8 \pm 2.2^{\mathrm{a}}$ & $51.5 \pm 3^{b}$ & a 0.007 \\
\hline & $\operatorname{PoAF}(+)$ & $45.6 \pm 0.57^{\mathrm{a}}$ & $46.4 \pm 1.5^{\mathrm{b}}$ & ${ }^{\mathrm{b}} \mathbf{0 . 0 0 2}$ \\
\hline \multirow[t]{2}{*}{$\operatorname{LVESD}(\mathrm{cm})$} & PoAF (-) & $3 \pm 0.36^{\mathrm{a}}$ & $3 \pm 0.38^{\mathrm{b}}$ & ${ }^{\mathrm{a}}<0.001$ \\
\hline & $\operatorname{PoAF}(+)$ & $3.5 \pm 0.1^{\mathrm{a}}$ & $3.5 \pm 0.15^{b}$ & ${ }^{b} 0.011$ \\
\hline \multirow[t]{2}{*}{ LVEDD $(\mathrm{cm})$} & PoAF (-) & $4.77 \pm 0.55^{\mathrm{a}}$ & $4.59 \pm 0.58^{b}$ & a 0.009 \\
\hline & $\operatorname{PoAF}(+)$ & $5.26 \pm 0.15^{\mathrm{a}}$ & $5.36 \pm 0.2^{\mathrm{b}}$ & b0.012 \\
\hline \multirow[t]{2}{*}{$\operatorname{LAD}(\mathrm{cm})$} & PoAF (-) & $2.9 \pm 0.45^{\mathrm{a}}$ & $3.1 \pm 0.45^{\mathrm{b}}$ & ${ }^{a}<0.001$ \\
\hline & $\operatorname{PoAF}(+)$ & $3.73 \pm 0.11^{\mathrm{a}}$ & $3.78 \pm 0.13^{\mathrm{b}}$ & b0.005 \\
\hline \multirow[t]{2}{*}{ RAD (cm) } & PoAF (-) & $3.44 \pm 0.56^{\mathrm{a}}$ & $3.36 \pm 0.52^{\mathrm{b}}$ & ${ }^{\mathrm{a}} \mathbf{0 . 0 0 2}$ \\
\hline & $\operatorname{PoAF}(+)$ & $4.1 \pm 0.17^{\mathrm{a}}$ & $4.18 \pm 0.18^{b}$ & ${ }^{b} 0.003$ \\
\hline \multirow[t]{2}{*}{$\operatorname{RVD}(\mathrm{cm})$} & PoAF (-) & $2.15 \pm 0.15^{\mathrm{a}}$ & $2 \pm 0.15^{\mathrm{b}}$ & ${ }^{\mathrm{a}} \mathbf{0 . 0 0 3}$ \\
\hline & $\operatorname{PoAF}(+)$ & $2.47 \pm 0.05^{\mathrm{a}}$ & $2.4 \pm 0.07^{b}$ & ${ }^{b}<0.001$ \\
\hline \multirow[t]{2}{*}{ Distal anostmosis $>2, n(\%)$} & PoAF (-) & $9(52.9)^{\mathrm{a}}$ & $11(73.3)^{b}$ & ${ }^{\mathrm{a}} 1.000$ \\
\hline & $\operatorname{PoAF}(+)$ & $1(33.3)^{\mathrm{a}}$ & $4(80)^{b}$ & ${ }^{\mathrm{b}} 1.000$ \\
\hline \multirow[t]{2}{*}{ Inotropic support, n(\%) } & PoAF (-) & $8(47)^{\mathrm{a}}$ & $9(60)^{b}$ & ${ }^{\mathrm{a}} 1.000$ \\
\hline & PoAF $(+)$ & $1(33.3)^{\mathrm{a}}$ & $3(60)^{b}$ & ${ }^{\mathrm{b}} 1.000$ \\
\hline \multirow[t]{2}{*}{$\mathrm{CC}$ time (min) } & PoAF (-) & & $58.9 \pm 22.5^{\mathrm{b}}$ & ${ }^{\mathrm{b}} 0.668$ \\
\hline & $\operatorname{PoAF}(+)$ & & $54.2 \pm 14.2^{\mathrm{b}}$ & \\
\hline \multirow[t]{2}{*}{ CPB time (min) } & PoAF (-) & & $109.2 \pm 42^{b}$ & \\
\hline & $\operatorname{PoAF}(+)$ & & $96.4 \pm 23.9^{b}$ & b 0.517 \\
\hline \multirow[t]{2}{*}{ Anesthesia time (min) } & $\operatorname{PoAF}(-)$ & $216 \pm 27.2^{\mathrm{a}}$ & $243.6 \pm 43.8^{b}$ & ${ }^{\mathrm{a}} 0.879$ \\
\hline & $\operatorname{PoAF}(+)$ & $218.6 \pm 29.9^{\mathrm{a}}$ & $236.4 \pm 33.2^{\mathrm{b}}$ & b 0.740 \\
\hline
\end{tabular}

Data are shown as mean \pm standard deviation or number (\%). EF $=$ Ejection fraction, LVESD $=$ Left ventriculer end-systolic diameter, LVEDD $=$ Left ventriculer end-diastolic diameter, LAD = Left atrial diameter, RAD = Right atrial diameter, $\mathrm{RVD}=$ Right ventriculer diameter, $\mathrm{CC}=$ Cross-clamp, $\mathrm{CPB}=$ Cardiopulmonary bypass, PoAF $=$ Postoperative atrial fibrillation. Evaluating patients with and without PoAF among OPCABG patients a, Evaluating patients with and without PoAF among On-pump CABG patients ${ }^{\mathrm{b}}$

in terms of $\mathrm{CC}$ time, $\mathrm{CPB}$ time in the On-pump CABG group.

Preoperative hsCRP, postoperative hsCRP, preoperative HSP70 and postoperative HSP70 levels were significantly higher in patients with PoAF who underwent OPCABG $(p=0.018, p=0.044, p<0.001$ and $p=0.047$; respectively). (Table 3 ).

Preoperative hsCRP, postoperative hsCRP, preoperative HSP70 and postoperative HSP70 values were significantly higher in patients with PoAF who underwent $\mathrm{CABG}$ with cardiopulmonary bypass $(p=0.013$, $p=0.009, p=0.011$ and $p<0.001 ;$ respectively) (Table 3).

\section{DISCUSSION}

Atrial fibrillation is an atrial activation and rhythm disorder in which the atrium loses its mechanical functions. This is often accompanied by a rapid and irregular ventricular rhythm. This occurs frequently after CABG operations, and in several studies the inci- 


\section{Table 3. Preoperative and postoperative change of HSP70 and hsCRP values between patients with and without PoAF in two surgical groups}

\begin{tabular}{|c|c|c|c|c|}
\hline Characteristics & & $\begin{array}{c}\text { Off-Pump } \\
(n=20)\end{array}$ & $\begin{array}{c}\text { On-Pump } \\
(n=20)\end{array}$ & $p$ value \\
\hline \multirow[t]{2}{*}{ Preoperative hsCRP (mg/dL) } & $\operatorname{PoAF}(-)$ & $72.6 \pm 10.6^{\mathrm{a}}$ & $52.5 \pm 25.8^{\mathrm{b}}$ & ${ }^{\mathrm{a}} 0.018$ \\
\hline & $\operatorname{PoAF}(+)$ & $89.5 \pm 7.5^{\mathrm{a}}$ & $92.9 \pm 36^{b}$ & b0.013 \\
\hline \multirow[t]{2}{*}{ Postoperative hsCRP (mg/dL) } & $\operatorname{PoAF}(-)$ & $97.4 \pm 15.7^{\mathrm{a}}$ & $125.6 \pm 36.8^{\mathrm{b}}$ & a 0.044 \\
\hline & $\operatorname{PoAF}(+)$ & $122.9 \pm 34.6^{\mathrm{a}}$ & $176.8 \pm 21.6^{\mathrm{b}}$ & ${ }^{b} 0.009$ \\
\hline \multirow[t]{2}{*}{ Preoperative HSP70 (ng/dL) } & PoAF (-) & $1.37 \pm 0.2^{\mathrm{a}}$ & $1.69 \pm 0.58^{\mathrm{b}}$ & ${ }^{\mathrm{a}}<0.001$ \\
\hline & $\operatorname{PoAF}(+)$ & $2.08 \pm 0.1^{\mathrm{a}}$ & $2.52 \pm 0.55^{\mathrm{b}}$ & b0.011 \\
\hline \multirow[t]{2}{*}{ Postoperative HSP70 (ng/dL) } & $\operatorname{PoAF}(-)$ & $1.73 \pm 0.35^{\mathrm{a}}$ & $2.13 \pm 0.71^{\mathrm{b}}$ & a 0.047 \\
\hline & $\operatorname{PoAF}(+)$ & $2.23 \pm 0.51^{\mathrm{a}}$ & $3.91 \pm 0.6^{\mathrm{b}}$ & ${ }^{b}<0.001$ \\
\hline
\end{tabular}

Data are shown as mean \pm standard deviation. hsCRP $=$ High-sensitivity C-reactive protein, HSP70 $=$ Heat shock protein $70, \mathrm{PoAF}=$ Postoperative atrial fibrillation. Evaluating patients with and without PoAF among OPCABG

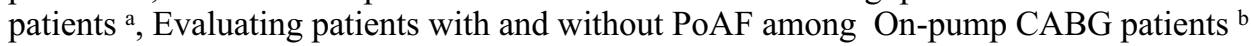

dence rates are given in the range of $20-50 \%$ [9]. According to data from the United States, PoAF can increase hospital costs [10]. The occurrence after coronary bypass surgery increases postoperative mortality and morbidity. In this study, we demonstrated that preoperative and postoperative elevated hsCRP and HSP70 levels were associated with the occurrence of PoAF in on pump CABG and OPCABG patients.

Although $\mathrm{CABG}$ operations using cardiopulmonary bypass are proved to be safe and effective, side effects can be occurred due to blood and foreign surface contact. Additionally, ischemia-reperfusion injury due to cross-clamping of the ascending aorta may also adversely affect other vital organs such askidney, intestines and brain [11]. In OPCABG these CPB-related effects have been avoided, and postoperative complications have been shown to be less [12]. One of the undesirable and common problems after these operations is PoAF.

After on pump CABG, the inflammatory response increases due to the CPB system, posing a risk for the development of PoAF [13]. However, in a study conducted by Lin et al. [14] OPCABG and on pump CABG PoAF rates were found to be similar. In our study, PoAF rates were similar between the two surgical groups.

The relationship of C-reactive protein (CRP) levels, that predicts the inflammation and tissue damage, and cardiovascular diseases has been extensively investigated in recent years. However, hsCRP values have become more prominent since more sensitive measurements are needed for the cardiovascular system. Plasma CRP shows a proinflammatory effect by clustering with blood lipids and activating the complement pathway [15].

Inflammation also poses a risk for $\mathrm{AF}$ and also plays a role in prolonging AF periods [16]. Because arrhythmia occurs as a result of fibrosis in atrial muscle structures and conduction pathways [7]. The most important reason for this is inflammatory processes. Accordingly, in a study by Ucar et al. [17] 49 patients who underwent on pump CABG were prospectively examined and the relationship between PoAF and inflammatory markers was investigated. In this study, the authors reported PoAF rates as $28.5 \%$ and found that hsCRPvalues collectedpreoperatively and postoperatively on the first day were significantly higher in the group developing PoAF [17]. In our study, we studied preoperative and postoperative 3rd day hsCRP values and found significantly higher in patients who developed PoAF in both surgical groups.

Heat shock proteins (HSPs) are heat-permeable gene products that protect cells against stress. HSP90, HSP70 and HSP60 belong to the first group family of these proteins [18]. HSP70 plays important intracellular roles in facilitating protein transport, preventing misfolding of newly synthesized polypeptide chains and preserving protein denaturation [19]. Many studies have shown increased HSP levels in atrial tissue in patients with paroxysmal or persistent AF [20, 21]. In 
a study by Mandal et al. [8], HSP 70 levels obtained from atrial tissue with AF found to be negatively correlated with PoAF development. In our study, HSP70 peripheral blood levels were found to be high in patients with PoAF in both surgical groups.

Although advanced age generally poses a risk in all surgeries, it is one of the most important risk factors for PoAF in patients undergoing CABG. Myocardial fibrosis and accumulating amyloid stores with increasing age lead to AF by causing reentries between the atria [22]. Studies have shown that advanged age is a risk factor for PoAF after cardiac surgery $[23,24]$. In our study, patients over 70 years of age were excluded, but age was higher in the PoAF group in both surgical groups.

Increased left atrial diameter and low ejection fraction are also risk factors for PoAF. This means increased fibrosis in the heart muscle and therefore increased inflammation. As a result, the risk for AF increases $[25,26]$. In our study, left atrial diameters, LVESD, LVESD and RVD were significantly higher and EF was significantly lower in patients with PoAF in both surgical groups.

\section{Limitations}

The most important limitations of our study includesmall number of the patients and single-centeredness. Another limitation is the fact that holter recording could not be used in rhythm follow-ups during the follow-up of the patients.

\section{CONCLUSION}

As a result, PoAF is undesirable for CABG operations. PoAF can be predicted by evaluating HSP70 and hsCRP values before coronary bypass operations. The importance of these blood parameters should be investigated by prospective and multicenter studies with high number of patients.

\section{Conflict of interest}

The author disclosed no conflict of interest during the preparation or publication of this manuscript.

\section{Financing}

The authors disclosed that they did not receive any grant during conduction or writing of this study.

\section{REFERENCES}

1. Öztürk C, Yavuz Ş. Effect of coronary artery bypass surgery on ventricular functions in patients with poor left ventricular function. Eur Res J 2019;5:502-9.

2. Güvenç O, Göncü MT, Engin M, Çayır MÇ, Özyazıcığlu AF. Effects of coronary endarterectomy on postoperative early results in long segment coronary artery disease. Eur Res J 2020;6:18792.

3. Ozsin KK, Sanrı US, Toktas F, Kahraman N, Demir D, Yavuz S. Effect of SYNTAX score II on postoperative atrial fibrillation in patients undergoing off-pump coronary artery bypass grafting surgery. Kuwait Med J 2019;51:366-72.

4. Erdolu B, As AK, Engin M. The relationship between the HATCH score, neutrophil to lymphocyte ratio and postoperative atrial fibrillation after off-pump coronary artery bypass graf surgery. Heart Surg Forum 2020;23:E88-92.

5. Szmitko PE, Wang CH, Weisel RD, de Almeida JR, Anderson TJ, Verma S. New markers of inflammation and endothelial cell activation: Part I. Circulation 2003;108:1917-23.

6. Conway DS, Buggins P, Hughes E, Lip GY. Prognostic significance of raised plasma levels of interleukin-6 and C-reactive protein in atrial fibrillation Am Heart J 2004;148:462-6.

7. Weymann A, Popov A-F, Sabashnikov A, Ali-Hasan-Al-Saegh $\mathrm{S}$, Ryazanov M, Tse G, et al. Baseline and postoperative levels of $\mathrm{C}$-reactive protein and interleukins as inflammatory predictors of atrial fibrillation following cardiac surgery: a systematic review and metaanalysis. Kardiol Pol 2018;76:440-51.

8. Mandal K, Torsney E, Poloniecki J, Camm AJ, Xu Q, Jahangiri M. Association of high intracellular, but not serum, heat shock protein 70 with postoperative atrial fibrillation. Ann Thorac Surg 2005;79:865-71.

9. Weymann A, Ali-Hasan-Al-Saegh S, Popov A-F, Sabashnikov A, Mirhosseini SJ, Liu T, et al. Hematologic indices as predictors of atrial fibrillation following isolated coronary artery bypass grafting, valvular surgery or combined procedures: a systematic review with meta-analysis. Kardiol Pol 2018;76:107-18.

10. Aranki SF, Shaw DP, Adams DH, Rizzo RJ, Couper GS, VanderVliet $\mathrm{M}$, et al. Predictors of atrial fibrillation after coronary artery surgery. Current trends and impact on hospital resources. Circulation 1996;94:390-7.

11. Baki ED, Aldemir M, Kokulu S, Koca HB, Ela Y, Sivacı RG, et al. Comparison of the effects of desflurane and propofol anesthesia on the inflammatory response and $\mathrm{s} 100 \beta$ protein during coronary artery bypass grafting. Inflammation 2013;36:1327-33. 12. Wijeysundera DN, Beattie WS, Djaiani G, Rao V, Borger MA, Karkouti K, et al. Off-pump coronary artery surgery for reducing mortality and morbidity: meta-analysis of randomized and observational studies. J Am Coll Cardiol 2005;46:872-82. 13. Bohatch Júnior MS, Matkovski PD, Di Giovanni FJ, Fenili R, Varella EL, Dietrich A. Incidence of postoperative atrial fibrillation in patients undergoing on-pump and off-pump coronary artery bypass grafting. Braz J Cardiovasc Surg 2015;30:316-24. 14. Lin WS, Liou JT, Yang SP, Tsai CS, Chung MH, Chu KM. Can off-pump coronary artery bypass graft surgery decrease the incidence of postoperative atrial fibrillation? Acta Cardiol Sin 2006;22:205-11. 
15. Kuller LH, Tracy RP, Shaten J, Meilahn EN. For the MRFIT Research Group: Relation of C- reactive protein and coronary heart disease in the MRFIT nested case-control study. Am J Epidemiol 1996;144:537-47.

16. Korantzopoulos P, Kolettis T, Siogas K, Goudevenos J. Atrial fibrillation and electrical remodeling: the potential role of inflammation and oxidative stress. Med Sci Monit 2003;9:RA225-9. 17. Ucar HI, Tok M, Atalar E, Dogan OF, Oc M, Farsak B, et al. Predictive significance of plasma levels of interleukin- 6 and high-sensitivity $\mathrm{C}$-reactive protein in atrial fibrillation after coronary artery bypass surgery. Heart Surg Forum 2007;10:E131-5. 18. Tavaria M, Gabriele T, Kola I, Anderson RL. A Hitchhiker's guide to the human Hsp70 family. Cell Stress Chaperones 1996;1:23-8.

19. Henderson B. Integrating the cell stress response: a new view of molecular chaperones as immunological and physiological homeostatic regulators. Cell Biochem Funct 2010;28:1-14.

20. Brundel BJ, Henning RH, Ke L, van Gelder IC, Crijns HJ, Kampinga $\mathrm{HH}$. Heat shock protein upregulation protects against pacing-induced myolysis in HL-1 atrial myocytes and in human atrial fibrillation. J Mol Cell Cardiol 2006;41:555-62.

21. Yang M, Tan H, Cheng L, He M, Wei Q, Tanguay RM, et al.
Expression of heat shock proteins in myocardium of patients with atrial fibrillation. Cell Stress Chaperones 2007;12:142-50.

22. Nisanoglu V, Erdil N, Aldemir M, Ozgur B, Berat Cihan H, Yologlu S, et al. Atrial fibrillation after coronary artery bypass grafting in elderly patients: incidence and risk factor analysis. Thorac Cardiovasc Surg 2007;55:32-8.

23. Turk T, Vural H, Eris C, Ata Y, Yavuz S. Atrial fibrillation after off-pump coronary artery surgery: a prospective, matched study. J Int Med Res 2007;35:134-42.

24. Geçmen Ç, Babür Güler G, Erdoğan E, Hatipoglu S, Guler E, Yilmaz F, et al. SYNTAX score predicts postoperative atrial fibrillation in patients undergoing on-pump isolated coronary artery bypass grafting surgery. Anatol J Cardiol 2016;16:655-61. 25. Huxley RR, Filion KB, Konety S, Alonso A. Meta-analysis of cohort and case-control studies of type 2 diabetes mellitus and risk of atrial fibrillation. Am J Cardiol 2011;108:56-62.

26. Faustino A, Providencia R, Barra S, Paiva L, Trigo J, Botelho A, et al. Which method of left atrium size quantification is the most accurate to recognize thromboembolic risk in patients with non-valvular atrial fibrillation? Cardiovasc Ultrasound 2014; $12: 28$. 